\title{
Applying Sight Translation as a Means to Enhance Reading Ability of Iranian EFL Students
}

\author{
Moslem Fatollahi ${ }^{1}$ \\ ${ }^{1}$ English Department, University of Zabol, Zabol, Iran \\ Correspondence : Moslem Fatollahi, English Department, University of Zabol, Mofatteh St., Jahad Sq., Zabol, \\ Sistan and Baluchistan Province, Iran. Tel: 98-918-641-2397. E-mail: m.fatollahi@uoz.ac.ir
}

Received: December 24, $2015 \quad$ Accepted: February 12, $2016 \quad$ Online Published: February 14, 2016
$\begin{aligned} & \text { doi: } 10.5539 / \text { elt.v9n3p153 } \\ & \text { URL: http://dx.doi.org/10.5539/elt.v9n3p153 }\end{aligned}$

\begin{abstract}
Sight translation is the oral translation of a written text and is a mixture of translation and interpreting. Sight translation is a widely-used activity in translation training programs. Yet, this mode of translation has rarely been applied as a reading instruction technique in Iranian EFL instruction context in spite of the growing interest in using sight translation in language teaching and learning. This study aims at investigating the effect of sight translation on the reading comprehension ability of Iranian undergraduate EFL students. This is a quasi-experimental study involving treatment. To this end, four reading comprehension classes involving 70 learners were divided into two groups, with the experimental one receiving reading instruction with sight translation exercises and the control group receiving reading instruction without sight translation exercises. The posttest results revealed that the experimental group performing sight translation exercises in classroom outperformed the control group who had not engaged in sight translation. This study has implications for ELT instructors and learners in an Iranian context as they can use sight translation exercises as an effective technique for improving the reading comprehension ability of their learners.
\end{abstract}

Keywords: sight translation, language teaching, reading ability, Iranian learners

\section{Introduction}

\subsection{Sight Translation}

As defined by Gonzalez, Vasquez and Mikkelson (2012), sight translation is the act of the oral translation of a written text and is a combination of translation and interpreting. In other words, sight translation is the oral reproduction in the Target Language (TL) of a document originally written in the Source Language (SL) for one or more receivers who may be listeners present in the same communicative situation where the translator is, or readers who want to read written record of the oral translation provided by the translator. As sight translation is rendered almost simultaneously for use of customers in a specific situation, it has also been called "sight interpreting" (Pochhacker, 2004).

Sight translation is a widely-applied activity in translation pedagogy. Sawyer (2004) refers to the fact that 30 to 50 percent of translation classes' time in Spain is spent on sight translation. Sight translation is a main component of the common translation programs. According to Sawyer, before the beginning of the $21^{\text {st }}$ century, sight translation was mainly regarded as a separate subject (p. 149). Training techniques for activities such as note-taking and sight translation are highly applicable for future interpreters so that interpreting is often considered as a language-processing activity (Pochhacker, 2007).

Matin (2014) believes that sight translation has attracted so much attention from researchers and scholars. In this regard, cognitive aspects of sight translation such as control of mind, and monitoring the speech are regarded as more fascinating subjects than grammar knowledge or memory. Paez (2012) is one of the experts who have made an attempt to describe the mental process of sight translation. He believes that interpreters should pass three important meta-cognitive phases in sight translation. These three phases need high cognitive and mental abilities, such as short-term memory, text scanning and task coordination (p. 96).

As Clavijo and Marine (2013) explain, Sight translation requires a quick analysis of a text and a creative, but exact, recreation of it. It might be applied as a stage of the procedure to prepare learners for the simultaneous and consecutive interpreting actions they are going to fulfill in future. Stansfield (2008) also considers sight 
translation as the most difficult task interpreters have to deal with. This is mainly due to the fact that other modes of interpreting are merely in oral language. The interpreter renders oral message into oral message in another language. But, sight translators may have to interpret written language into oral language, often without the opportunity to carefully prepare for it (p. 86). Corselis (2008) also regards sight translation of texts longer than 100 words to be quite challenging for interpreters (p. 61).

Most translation techniques used in professional translation, such as sight translation, are regarded to be effective learning techniques and fascinating for students because learners understand that they are fulfilling authentic activities. In this regard, translation tasks can effectively be used in language learning (Davies, 2005). O'Malley and Chamot (1990) also believe that translation (defined as applying L1 for comprehending and producing L2) encompasses more than one third of strategies applied in language learning so that beginners mainly use reiteration, translation and transliteration. On the other hand, higher level learners apply comprehension techniques besides repetition and translation (p. 127).

There seems to be some sort of connection between writing ability and sight translation. Friedlander(1990) postulates that translation from the first language into English helps English learners to come up with a much more coherent text in English as they can use more data when working in their native language. Friedlander proposes that EFL learners be motivated to apply their native language to write a draft and then render it into English (pp. 110-113).

As Popovic (2001) puts it, considering the fundamentality of learner-focused language teaching, any activity that assists language learning should be utilized. Therefore, academicians and professionals have been trying to realize what new techniques can be used in ELT. In this regard, Translation as an instrument of language teaching is now being more emphasized by language instructors and learners (p. 2).

\subsection{Aims of the Present Study}

As discussed in the previous section, sight translation is a central issue in interpreter training programs and interpreting studies. On the other hand, it has considerable potential as a means to enhance language skills. Despite its high potential, sight translation has rarely been regarded as a language teaching tool especially in Iranian TEFL context.

This study aims at investigating the effect of sight translation on the reading comprehension ability of Iranian undergraduate EFL students. In this regard, two research questions are posed as the main and subsidiary questions of the study, respectively.

Q1: Is there a significant difference between reading acquisition of learners performing sight translation and that of learners who do not perform sight translation?

Q2: Does gender have a significant mediating effect on the role of sight translation in reading ability acquisition.

To answer the above questions, authors propose the following null hypotheses, respectively. In fact, authors predict the first hypothesis to be rejected and the second one to be proved:

H1: There is no significant difference between reading acquisition of learners performing sight translation and that of learners who do not perform sight translation.

H2: Gender has no significant mediating effect on the role of sight translation in reading ability acquisition.

\subsection{Review of Literature}

Sight translation is a widely studied notion in translation studies. Obidina (2015) conducted a study to analyze sight translation as a mixed mode of translation action. She strived to provide insights into the stance of sight translation in the language teaching and learning syllabi, translator and interpreter training programs, linguistic studies and language industry. Her discussion reveals that Sight translation as a mixed mode of translation action basically needs more focus from researchers and language instructors. As she puts it, sight translation training should be developed due to high demand for this mode of translation in the market (see also Agrifoglio, 2002; Biela-Wolonciej, 2007; Pelin, 2014).

Chen and Ko (2010) designed and administered an online test for professional interpreting, in which sight translation tasks were used as well as dialogue interpreting and consecutive interpreting tasks. The findings of their study revealed the potential and applicability of administering online interpreting tests by incorporating the applications of synchronous cyber classrooms.

Drugsted, Mees, and Hansen (2011) investigated the translation procedures and outputs of MA students who rendered texts from Danish into English in different working circumstances, say written translation and sight 
translation. Audio products and keyboard moves were recorded. Translation data were investigated in order to realize if time and quality were different in the three mentioned modes or not. Their results indicated that task times were highest in written translation, but the quality level was not significantly higher.

Pedersen and Dam (2014) conducted a study to realize if sight translation needs the use of short-term memory during the process of target-text production, as reported in the literature, or not. Their study was based on a former study involving sight translation tasks from Spanish into Danish. Translators were also interviewed after completing the tasks. Their findings revealed that that the participants widely needed short-term memory in the process of sight translation (see also Huang, 2011).

Felberg and Akershus (2015) conducted a study to realize why some interpreters need more time than their peers for completing sight translation tasks in asylum-seeking context. The research hypothesis was that slow rate of sight translation is mainly due to a mixture of three causes: interpreters' poor reading abilities; their inefficient interpreting skills; and/or their unfamiliarity with the appropriate genre/style. Their research findings revealed that besides the mentioned factors, variables such as the interviewer's knowledge of interview tips; the interviewer's skill in producing written records of oral data; the asylum seekers' narrative skills; and the asylum seekers' capability of compensating for the mistakes in their written report.

Chmiel and Mazur (2013) explored the role of different factors in sight translation success. They observed the performance of interpreting learners during training and realized that readability of the intended text is much more effective in sight translation success than simplicity or complexity of text structure(see also Gorszczyńska \& Gdansk, 2010).

Despite the wide range of literature on sight translation, few studies have explored the role of this translation mode in language learning. A few related studies have been provided in Discussion section for consolidating the results of the present study.

\section{Methodology}

As mentioned earlier, this study is an attempt to investigate the effect of sight translation in enhancing reading comprehension ability of undergraduate EFL students in an Iranian context. This is a quasi-experimental study involving treatment. To this end, four reading comprehension classes at the University of Zabol, Iran, were selected as research sample; based on convenient sampling. A total number of 70 students, 38 females and 32 males, had been registered in the two classes. All participants were sophomore students taking their third and final four-credit course on reading comprehension.

Students were initially administered the reading comprehension section of the TOLIMO (the Test of Language by the Iranian Measurement Organizations) which is based on PBT TOEFL, for their homogeneity in terms of reading comprehension ability to be confirmed. Upon completion of pretest, two classes were regarded as control group and two others as experimental group. The first group received the common reading instruction method and the second one received the same method plus sight translation exercises. In the experimental classes, some part of classroom time was spent on sight translation exercises in which students were obliged to read textbook English passages and simultaneously render them into speech into Persian. About one fourth of the class hour was spent on sight translation. Treatment was performed during eleven sessions of an academic semester.

Upon completion of the treatment, a posttest which was a different version of TOLOMO reading comprehension test was administered to the participants of both control and experimental groups to investigate if there were any significant difference between the two groups in terms of the reading comprehension ability. All statistical results obtained for pretest and posttest were recorded and analyzed using SPSS Version 22. Pearson Correlation Coefficient and Independent Samples T-test were used for data analysis. Then, research hypotheses were investigated, findings were discussed, and some pedagogical implications were provided.

\section{Results and Discussion}

As mentioned earlier, this study aimed at investigating the effect of sight translation tasks on reading acquisition of undergraduate ELT students in the Iranian context. To confirm the homogeneity of the research sample in terms of reading ability, a pretest was administered to the test-takers. The pretest results are shown in Table 1. Further, the Independent Samples T-Test results for pretest are given in Table 2. 
Table 1. Descriptive statistics for pretest

\begin{tabular}{lllll}
\hline Group & $\mathrm{N}$ & Mean & Std. Deviation & Std. Error Mean \\
\hline Experimental & 35 & 25.29 & 6.600 & 1.116 \\
Control & 35 & 25.46 & 5.938 & 1.04 \\
\hline
\end{tabular}

Table 2. Independent samples T-Test for pretest

\begin{tabular}{lllll}
\hline \multicolumn{7}{l}{ T-test for Equality of Variances } & & \\
\hline $\mathbf{t}$ & $\mathrm{df}$ & $\mathrm{Sig}(2$-tailed $)$ & Mean Difference & Std. Error Difference \\
-0.114 & 68 & 0.909 & -0.171 & 1.501 \\
\hline
\end{tabular}

As seen in Table 1, the average reading comprehension score of the test-takers of experimental and control groups are 25.29 and 25.46 respectively, which shows close mean scores for the two groups. Further, the standard deviations for experimental and control groups are 6.6 and 5.9, respectively.

To confirm the homogeneity of the two groups' reading scores, an Independent Samples T-test was run. As seen in Table 2, results of the Levene's Test for equality of variances is $0.445(>0.05)$ which approves equality of variances for the two groups. On the other hand, result of the critical T-test score for equality of means is 0.909 which approves the null hypothesis of the pretest at a 0.05 level of confidence. In other words, there is no significant difference between the reading scores of the two groups and two groups are homogeneous in terms of their reading comprehension ability.

After completion of 11 sessions of treatment, test-takers of the two groups were administered another version of TOLIMO reading comprehension test, in order for their level of progress in reading ability to be investigated. The descriptive statistics for the posttest results of the two groups are given in Table 3. Further, the Independent Samples T-test results for posttest are provided in Table 4.

Table 3. Descriptive statistics for the two groups' posttest results

\begin{tabular}{lllll}
\hline Group & $\mathrm{N}$ & Mean & Std. Deviation & Std. Error Mean \\
\hline Experimental & 35 & 25.14 & 6.594 & 1.115 \\
Control & 35 & 32.29 & 5.924 & 1.001 \\
\hline
\end{tabular}

Table 4. Independent samples T-Test for posttest

\begin{tabular}{lllll}
\hline \multicolumn{1}{l}{ T-test for Equality of Variances } & & \\
\hline $\mathbf{t}$ & $\mathrm{df}$ & $\mathrm{Sig}(2$-tailed) & Mean Difference & Std. Error Difference \\
-2.098 & 68 & 0.040 & -3.143 & 1.498 \\
\hline
\end{tabular}

To investigate the difference between groups' reading scores after receiving reading instruction, an Independent Samples T-test was run. As seen in Table 4, results of the Levene's Test for equality of variances is $0.394(>0.05)$ which approves equality of variances for the two groups. On the other hand, result of the critical T-test score for equality of means is 0.04 which does not approve the null hypothesis of the posttest at a 0.05 level of confidence. In other words, as the first null hypothesis of this study is not approved, it is revealed that there is a significant difference between the reading scores of the two groups. In other words, the mean score of posttest reading ability of the experimental group is significantly higher than that of the control group receiving the substitute method of reading instruction.

As to the second research hypothesis of the study, the mediating effect of gender on the role of sight translation in enhancing reading comprehension ability of the participants was investigated. To this end, another Independent Samples T-test was run. The T-test results are given in Table 6. Further, the descriptive statistics for the two sexes' results are provided in Table 5. 
Table 5. Descriptive statistics for the two sexes' posttest results

\begin{tabular}{lllll}
\hline Group & $\mathrm{N}$ & Mean & Std. Deviation & Std. Error Mean \\
\hline Female & 38 & 30.74 & 6.542 & 1.061 \\
Male & 32 & 30.69 & 5.378 & 1.127 \\
\hline
\end{tabular}

Table 6. Independent samples T-Test for the two sexes' posttest scores

\begin{tabular}{lllll}
\hline \multicolumn{4}{l}{ Independent } & Samples T-Test \\
\hline $\mathrm{T}$ & $\mathrm{df}$ & $\mathrm{Sig}(2$-tailed) & Mean Difference & Std. Error Difference \\
0.032 & 68 & 0.975 & 0.049 & 1.552 \\
\hline
\end{tabular}

As seen in Table 5, the mean posttest reading scores of females (30.74) is slightly higher than that of males (30.69). The standard deviations of the two groups' scores are also close to each other. On the other hand, as seen in Table 6, results of the Levene's Test for equality of variances is $0.703(>0.05)$ which approves equality of variances for the two sexes. On the other hand, result of the critical T-test score for equality of means is 0.049 which does not approve the second null hypothesis of the posttest at a 0.05 level of confidence. In other words, as the second null hypothesis of this study is not approved, it is revealed that there is a significant difference between the reading scores of the males and females. In other words, the mean score of posttest reading ability of the female group is significantly higher than that of the male group. This is to say that gender slightly modifies the effect of sight translation on reading comprehension improvement of the participants.

These results are in line with several studies in the literature and support the use and applicability of sight translation as a translation mode in language teaching and learning. For example, Zarrabi Ajami (2014) explored the role of translation in ELT as perceived by Iranian instructors and learners at private institutes. His findings had revealed the important role of translation in teaching various language skills. Asadnejad (2012)'s study is another example which had supported the positive role of translation as a means to teach relative clauses. Mashhady (2006) is another researcher who used translation as a means to test reading ability of Iranian EFL learners.

\section{Conclusion and Pedagogical Implications}

In this study, we aimed to investigate the effect of sight translation tasks in improving reading comprehension ability of undergraduate EFL students at an Iranian context. All in all, our findings revealed the positive effect of sight translation on acquiring reading comprehension ability among the participants. Further, our study supported a significant mediating role for gender regarding the effect of sight translation on reading ability acquisition.

This study has implications for ELT instructors and learners in an Iranian context as they can use sight translation as an effective technique for improving the reading comprehension ability of their learners. These exercises have almost the same positive effect on both male and female learners.

Like any other research, this study is limited in some aspects. This study was conducted in an Iranian university. Although students of this university come from different parts of the country, results of this study can only be generalized with caution. Further, usefulness of sight translation tasks in private non-academic ELT contexts should be determined through separate studies.

\section{References}

Agrifoglio, M. (2002). Sight Translation and Interpreting: A Comparative Analysis of Constraints and Failures. Interpreting, 6(1), 43-67. http://dx.doi.org/10.1075/intp.6.1.05agr

Asadnejad, A. (2012). The Role of Translation in Teaching Relative Clauses: Facilitator or Impeder? Proceedings of the First Interdisciplinary Conference on Language Teaching And Learning. October 30-31, Ferdowsi University of Mashhad, Iran.

Biela-Wolonciej, A. (2007). A-Vista: New Challenges for Tailor-Made Translation Types on the Example of Recorded Sight Translation. Kalbotyra, 57(3), 30-39.

Chen, N.-S., \& Ko, L. (2010). An Online Synchronous Test for Professional Interpreters. Educational Technology \& Society, 13(2), 153-165.

Chmiel, A., \& Mazur, I. (2013). Eye tracking sight translation performed by trainee interpreters. In C. Way, S. 
Vandepitte, R. Meylaerts, \& M. Bartłomiejczyk (Eds.), Tracks and Treks in Translation Studies. Selected Papers from the EST Congress, Leuven 2010 (pp. 189-205). Amsterdam: John Benjamins. http://dx.doi.org/10.1075/btl.108.10chm

Clavijo, B., \& Marine, P. (2013). Identifying Translation Teaching Strategies: An Exploratory Study. International Journal of Humanities and Social Science, 3(21), 71-78.

Davies, M. G. (2006). Minding the Process, Improving the Product Alternatives to Traditional Translator Training. In M. Tennent (Eds). Training for the New Millennium. Amsterdam \& Philadelphia: Benjamins.

Dragsted, B., Mees, I. M., \& Hansen, I. G. (2011). Speaking Your Translation: Students' First Encounter with Speech Recognition Technology. Translation \& Interpreting, 3(1), 10-43.

Felberg, T. R., \& Akershus, H. O. (2015). Utfordringer ved Prima Vista Tolking i Asylintervjuer. Scandinavian Journal of Intercultural Theory and Practice, 2(1), 1-17.

Friedlander, A. (1990). Composing in English: Effects of a First Language on Writing in English as a Second Language. In B. Kroll (Ed.), Second Language Writing: Research Insights for the Classroom. Cambridge: Cambridge University Press. http://dx.doi.org/10.1017/CBO9781139524551.012

Gonzalez, R. D., Vasquez, V. F., \& Mikkelson, H. (2012). Fundamentals of Court Interpreting: Theory, Policy, and Practice. Durham: Carolina Academic Press.

Gorszczyńska, P. (2010). The Potential of Sight Translation to Optimize Written Translation: the Example of the English-Polish Language Pair. In O. Azadibougar (Ed.), Translation Effects. Selected Papers of the CETRA Research Seminar in Translation Studies 2009. http://www.kuleuven.be/cetra/papers/papers.html

Huang, C. C. (2011). Tracking Eye-Movements in Sight Translation- the Comprehension Process in Interpreting. M.A. Thesis, National Taiwan Normal University.

Mashhady, H. (2006). Translation as a Means of Testing Reading Ability of EFL Students. Translation Studies, 4(14), 9-28.

Matin, R. M. (2014). A Blurred Snapshot of Advances in Translation Process Research. MonTI Special Issue Minding Translation: 49-84.

Obidina, V. V. (2015). Sight Translation: Typological Insights into the Mode. Journal of Siberian Federal

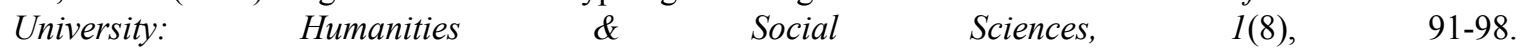
http://dx.doi.org/10.17516/1997-1370-2015-8-1-91-98

O’Malley, J, \& Chamot, A. U. (1990). Learning Strategies in Second Language Acquisition. Cambridge: Cambridge University Press. http://dx.doi.org/10.1017/CBO9781139524490

Paez, B. (2012). Performance Criteria Descriptors for Cognitive Processing Skills Used in Sight Translating. Current Trends in Translation Teaching and Learning, 4(4), 15-32.

Pelin, S. (2014). A Study on the Problems Encountered in Sight Translation. Celal Bayar University Journal of Social Sciences, 12(3), 1-13.

Pedersen, E. H., \& Dam, H. V. (2014). Short-Term Memory in the Production Phase of Sight Translation. Hermes, 52, 93-105.

Pochhacker, F. (2004). Introducing Interpreting Studies. London \& New York: Routledge.

Pochhacker, F. (2007). Critical Linking Up: Kinship and Convergence in Interpreting Studies. In C. Wadensjo, B. Dimitrova, \& A. Nilsson (Eds.), The Critical Link 4. Amsterdam \& Philadelphia: Benjamins. http://dx.doi.org/10.1075/btl.70.04poc

Popovic, R. (2001). The Place of Translation in Language Teaching. Paper in English Teaching Forum, 37, 2. Retrieved from www.sueleatherassociates.com/pdfs/Article_translationinlanguageteaching.pdf

Sawyer, D. B. (2004). Fundamental Aspects of Interpreter Education: Curriculum and Assessment. Amsterdam \& Philadelphia: Benjamins. http://dx.doi.org/10.1075/btl.47

Stansfield, C. W. (2008). A Practical Guide to Sight Translation of Assessments. A Report Submitted to the Second Language Testing Incorporation.

Zarrabi Ajami, M. R. (2014). Using Translation in Teaching and Learning English as a Foreign Language: Learners' and Instructors' Perspectives. M. A. Thesis, Ferdowsi University of Mashhad, Iran. 


\section{Copyrights}

Copyright for this article is retained by the author(s), with first publication rights granted to the journal.

This is an open-access article distributed under the terms and conditions of the Creative Commons Attribution license (http://creativecommons.org/licenses/by/3.0/). 